This item was submitted to Loughborough's Research Repository by the author.

Items in Figshare are protected by copyright, with all rights reserved, unless otherwise indicated.

\title{
Collaborative working in highways major maintenance projects
}

PLEASE CITE THE PUBLISHED VERSION

https://doi.org/10.1680/mpal.2009.162.2.59

\section{PUBLISHER}

(c) Institution of Civil Engineers

\section{VERSION}

VoR (Version of Record)

\section{PUBLISHER STATEMENT}

This work is made available according to the conditions of the Creative Commons Attribution-NonCommercialNoDerivatives 4.0 International (CC BY-NC-ND 4.0) licence. Full details of this licence are available at: https://creativecommons.org/licenses/by-nc-nd/4.0/

\section{LICENCE}

CC BY-NC-ND 4.0

\section{REPOSITORY RECORD}

Ansell, Mary, Rees J.E. Evans, Michael Holmes, Andrew D.F. Price, and Christine L. Pasquire. 2019.

"Collaborative Working in Highways Major Maintenance Projects". figshare. https://hdl.handle.net/2134/26182. 

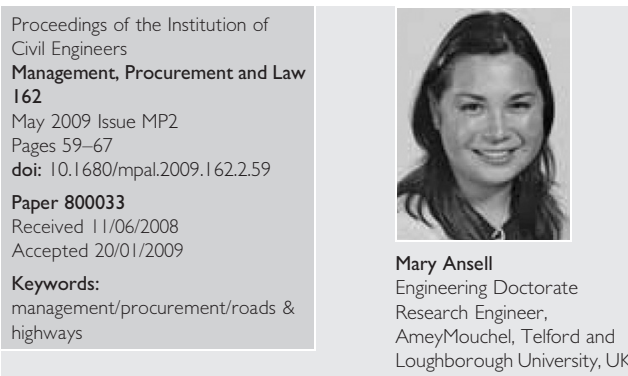

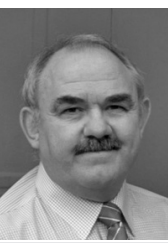

Rees Evans Engineering and Deliver Manager, AmeyMouche Birmingham, U

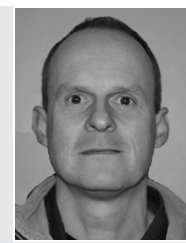

Mike Holmes Construction Team Leader, AmeyMouchel, Telford, UK

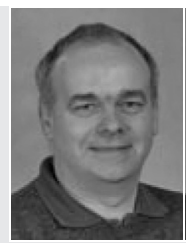

Andrew Price

Professor, Finance Director/ Director for Postgraduate Loughborough University, UK

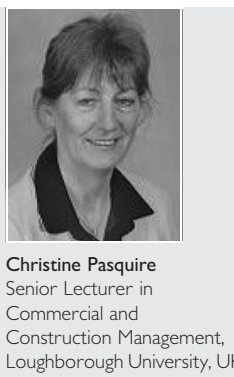

\title{
Collaborative working in highways major maintenance projects
}

\author{
M. Ansell MSc, CEng, MICE, R. Evans CEng, MICE, M. Holmes CEng, MICE, A. Price PhD and C. Pasquire PhD
}

Over the last decade, there has been a growing emphasis on collaborations and partnering in the construction industry. This has been embraced in the UK highways maintenance sector, with partnering promoted by the client, leading to the formation of alliances and partnering frameworks. One of these is the construction management framework (CMF), the preferred method of procurement for major maintenance projects in the Highways Agency's areas 9 and 10. This paper compares two road and structure renewals schemes carried out using the CMF. The first scheme was carried out in 2004 as one of the first of its type to be undertaken by the CMF; the second was a similar project carried out in 2006. Documentation of the two projects was reviewed to identify the benefits that were gained through working in collaboration, and if there was an improvement in performance as the framework became more established. The research considered key performance indicators, including cost and time predictability measures, respect for people surveys, innovations and lessons learned discussed at the time of the projects, and instructions for changes to works information. Data collected from both schemes show improvements in measurement and culture fostered by the CMF, and the advantages of the processes used are illustrated.

\section{INTRODUCTION}

The Highways Agency (HA) was created in 1994 as an executive agency to manage and maintain England's motorway and trunk road network, a role that had previously been undertaken by local and central government. ${ }^{1}$ When the HA was first established, there were 91 separate agency agreements in existence for works on the network that included routine, winter and capital maintenance, as well as inspections of the network, accident and incident investigation and data provision. ${ }^{1}$ In 1996, the HA responded to demands for greater efficiency in the public sector by opening its agreements to competitive tender from both the public and private sectors, and reducing the number of agreements to 24 ; this was later further reduced to 20 and is currently established at $14 \mathrm{HA}$ areas. ${ }^{1}$ Each HA area has an area team and a contractor, known as the managing agent (MA) or managing agent contractor (MAC), who are responsible for maintaining the roads within the area, up to works costing $£ 5$ million. ${ }^{2}$ Projects costing more than this are the responsibility of the major projects directorate, or may be managed under a private finance initiative. ${ }^{2}$
The construction management framework (CMF) was established by the HA in 2002 to carry out highways major maintenance and renewals work in two of the HA areas: 9 and 10. The CMF is defined as: 'A collection of companies and organisations, bound together by a series of collaborative processes and principles that have formed a unique 'Community' delivering a service to the Highways Agency under the route of Construction Management in Areas 9 and $10{ }^{3}$

This paper considers two projects undertaken by the CMF in area 9. Both schemes were undertaken on a $1 \mathrm{~km}$ stretch of viaduct in the Birmingham area. The first project, $\mathrm{P} 1$, was undertaken in 2004 on the southbound carriageway of the viaduct, involving the removal of the existing surfacing and waterproofing, repairs to the concrete deck, replacement of the waterproofing and surfacing works, including installation of asphaltic plug joints. The works were carried out under a $2 \times 2$ contraflow (two lanes flowing in each direction) with all traffic diverted onto the northbound carriageway allowing work to be carried out under a full closure to public traffic. The project was one of the first to be carried out by the CMF in area 9 , and the project team had not worked together before.

The second project, P2, was undertaken in 2006 on the northbound carriageway of the viaduct, and, in principle, involved the same work carried out on the opposing side 2 years earlier (see Figure 1). By this stage, the CMF had completed a number of schemes in Area 9, and the same team of designers, contractors and construction manager had worked together on two previous projects.

The research compared the two projects which are part of a programme of works carried out using the CMF. These two projects were specifically chosen as examples of work undertaken within the CMF because they were similar works which were easily comparable, and because they were undertaken at different times during the life of the framework. P1 was carried out when the framework was first established and processes and relationships were new, whereas P2 was carried out 2 years later when these were more developed. The research was performed to identify any improvements from the first project to the second, to identify whether there are benefits to using the CMF model for repeat projects and also to look at lessons learned, how these are captured and used to improve performance. 


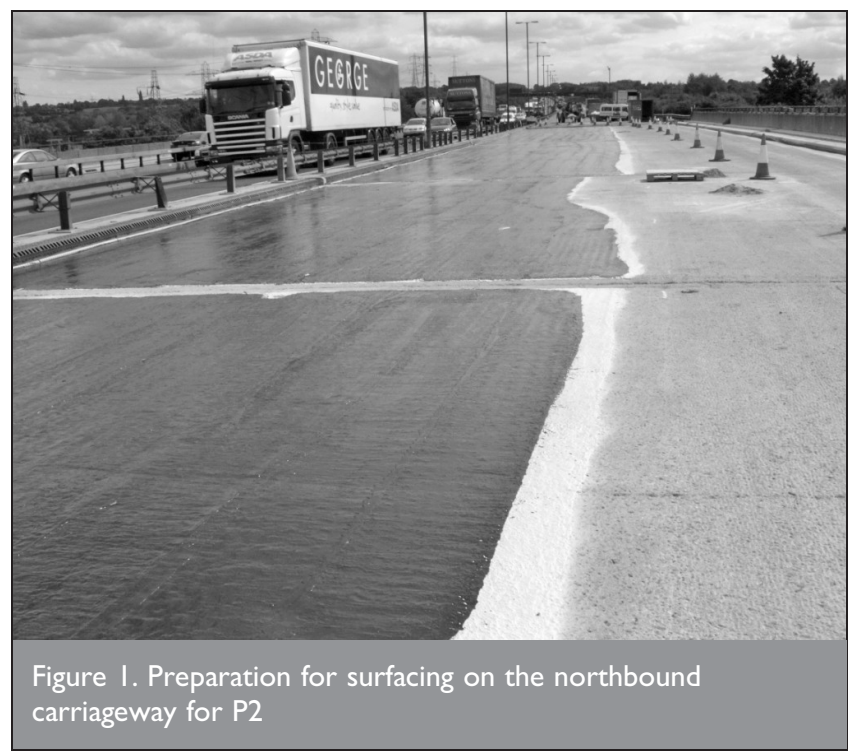

The assessment includes a review of the key performance indicator (KPI) results from both projects, which encompasses customer and client satisfaction, predictability of time and cost and site safety. In addition, a comparison of the cost and duration of the projects is made, with an index applied to take into account inflation. The lessons learned and innovations discussed during the projects have been compared. 'Respect for people' surveys were carried out on site to gauge worker satisfaction, and these have been compared for the two schemes. Finally, communications on site are recorded on a site record system, and this includes early warning which may result in a compensation event. The number of changes to works information have also been compared as well as the value of compensation events resulting from these.

\section{BACKGROUND TO THE CMF}

In 2001, the HA published a procurement strategy identifying good procurement practice and good relationships with their supply chain as essential to its business of providing services to road users. ${ }^{4}$ The strategy was developed following a review of a number of reports, starting with the Latham report ${ }^{5}$ and ending with the National Audit Office report: Modernising

Construction. ${ }^{6}$ These reports, with others, identified the need for improvements in the construction industry, and pointed to longterm relationships with and between clients and their supply chain to replace competitive tendering. ${ }^{7}$ Within the procurement strategy of the HA, there was a recommendation for forward planning over a 3-year period of regional road and structures works (these being projects costing above the threshold for maintenance works - that is, $£ 500000$ for MAC contracts, and below $£ 5$ million), and then for these works to be packaged together and procured through framework arrangements. The use of frameworks was identified by the HA as providing better value for money than the procurement of projects on an individual basis, and where an adequate workload of a consistent and continuous nature exists, it was recommended that frameworks are used, this being done on an area and regional basis. ${ }^{3}$

The procurement strategy was written after two construction management pilots, where the HA entered into direct contractual relationships with specialist trade contractors, and a construction manager was employed for the overall management and coordination of the projects (Figure 2). ${ }^{8}$ In the first pilot, the specialist contractors were given the opportunity to provide input to schemes at design stage in an early contractor involvement (ECI) process. The KPIs were established at the beginning of the first pilot, with these including measures beyond cost, quality and time objectives, such as client involvement in the project, and the sharing of knowledge, expertise and resources between designers and contractors. ${ }^{8}$ To capture knowledge gained from the project, project performance was reviewed on completion of construction and key lessons learned were recorded. ${ }^{8}$ These initiatives were broadened in the second pilot, where companies were selected to participate in the scheme based on an 80/20 quality/price basis, with quality including an assessment of company attitude to partnering, and a self-supporting 'community' was formed, with various groups set up to guide the community, including a board, issues group and measurement group. ${ }^{9}$

The pilots were seen to be successful, with the HA winning the Contract Journal's client of the year award in 2001 for its work in the two schemes. ${ }^{9}$ It was decided construction management would be used for the delivery of road and structures renewal projects in areas 9 and 10 covering parts of the West Midlands and the north-west; the 4-year contract began in 2002. The contract was based on a modified version of option $C$ of the NEC Engineering and Construction Contract: 'option beta' based on target cost, with special conditions including a requirement for specialist framework contractors to contribute to continuous improvement and innovation. ${ }^{10}$ Construction management was used as the procurement route, so that separate contracts existed between the HA and each specialist framework contractor, the construction managers and the designers. An extension was granted in 2006, so that the contract would end in 2009.

At the beginning of the contract, the various companies comprising the framework formed a community guided by 'offline' groups for culture, measurement and processes to formulate and disseminate procedures and practices aligned with the shared vision of the community. ${ }^{8}$ This would ensure practices on CMF projects were consistent, although project teams and types of works differed. Providing this consistency has allowed comparisons across schemes to be made, and trends through time could be monitored. 
The CMF is one of four HA frameworks currently operating, the others being: the south-east framework for highways and structures (for areas 3, 4, 5, 6 and 8); the Midlands works framework 3 (for areas 7 and 11); and the area 12 works framework. The frameworks all adopt the HA's procurement practices of quality/price contractor selection and contracts paid on a cost reimbursable basis against an agreed target price. However, the CMF differs in that it is a community of companies covering a number of specialisms that have attempted to cultivate a uniform culture and shared practices, with specialists working on a level platform with designers and the construction manager because of their direct contractual relationship with the client. Frameworks operating in other parts of the country consist of four or five main contractors with their own supply chain; in the case of the south-east framework, five main contractors comprise the framework, working across five HA areas and delivering projects in relative isolation. ${ }^{11}$ The CMF presents opportunities for shared learning and continuous improvement through the creation of the 'offline' groups and organised community forums and workshops, as well as raising contractors of second-tier supply chains to first-tier specialist framework contractors, giving the client easier access to supply chain expertise.

\section{KEY PERFORMANCE INDICATORS}

In 2002, the off-line measurement group within the CMF community established 12 key performance indicators (KPIs), 10 of which are (a) customer satisfaction

(b) site safety

(c) time predictability

(d) cost predictability

(e) predictability of accruals forecasting

(f) defect-free work

(g) client satisfaction with product

(h) client satisfaction with service

(j) road traffic accidents

(k) final account settlement.

The KPI results for the two schemes are shown in Figure 3, which includes sub-measures for customer satisfaction, site safety, time and cost predictability and final account settlement. All scores were marked out of 10 . Some scores were subjective, with some adjudication by the measurement group; however, it should be noted that the measurements were completed by the same group of people in both schemes, thus allowing for consistency in the judgements made.

In research carried out regarding the delivery of best value in projects procured using the CMF, some measures were considered to be more important than others. ${ }^{12}$ The results of a questionnaire sent to those companies included in the CMF showed differences in what the client regarded as important, and what the remainder of the parties involved (namely the construction manager, specialist framework contractors and supply chain) regarded as significant. There was agreement that cost predictability and safety should both be given the

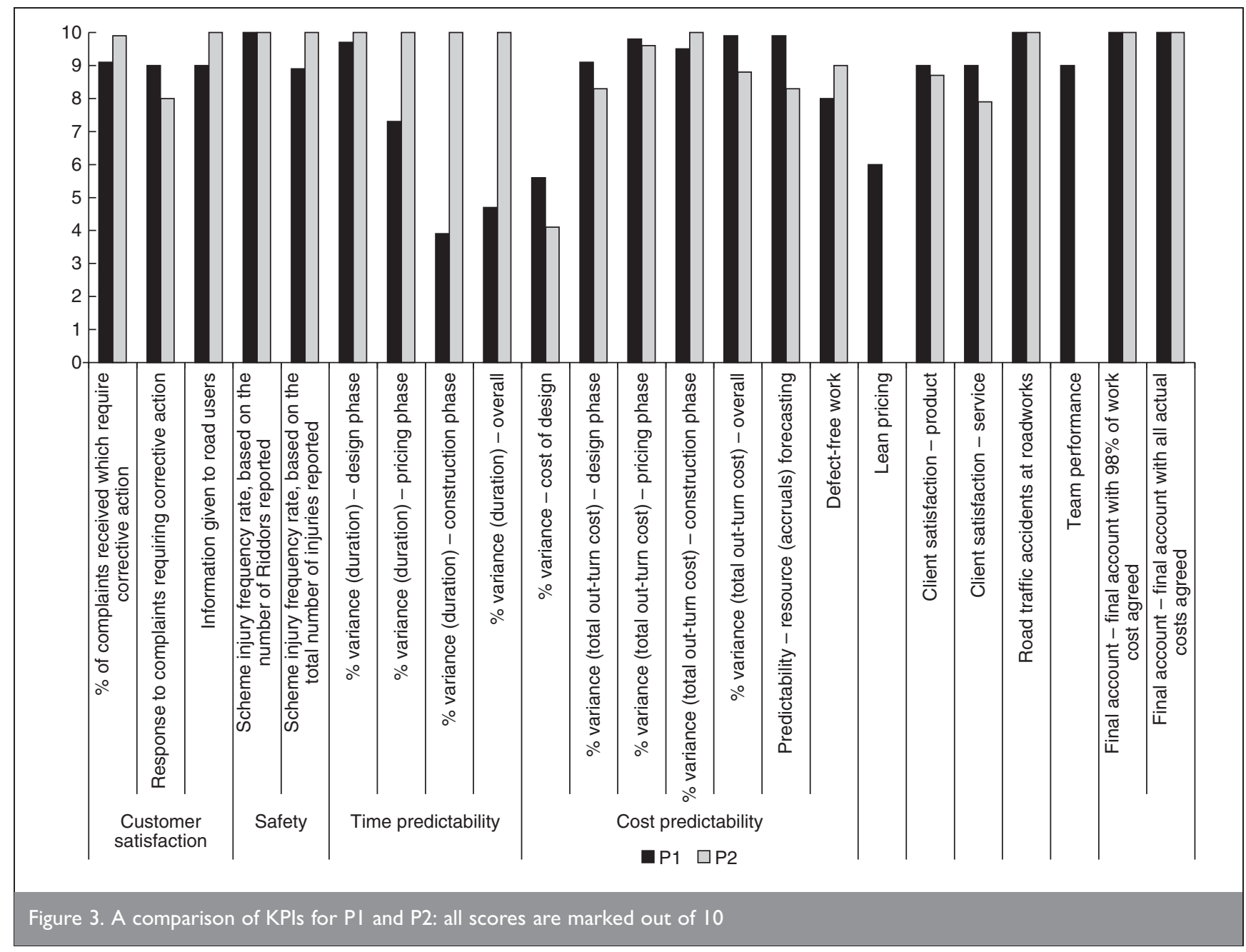


highest consideration; however, following this, there was some discrepancy. Customer satisfaction, defect-free work and lean pricing were then thought to be important by the client; for the remainder of the community, predictability of time, client satisfaction with service and client satisfaction with product were thought to contribute significantly to delivering best value.

From the results of the measurement, there are improvements shown from $\mathrm{P} 1$ to $\mathrm{P} 2$, particularly with regard to time predictability. For example, in P1, the actual duration of the construction phase was 34\% longer than that predicted at the client's commitment-to-invest point (following feasibility and value management of the scheme), producing a KPI score of 3.9. In P2, the team improved on this by completing the construction phase within the predicted duration, thus achieving a KPI score of 10. The other measures for time predictability (of design, pricing and overall) also improved to the extent that every phase was delivered within the duration predicted at the commitment-to-invest point in P2, where this was not achieved in the first scheme.

While time predictability was identified by the construction manager, specialist framework contractors and supply chain as contributing significantly to delivering best value but not by the client, it is inevitably associated with cost predictability, which is agreed to be significant by the parties surveyed. The results show a decrease in KPI scores for four of the five cost predictability sub-measures from P1 to P2. The lowest score for both P1 and P2 for cost predictability was assigned for the cost of design; in both schemes the cost of design was lower than that predicted at the client's commitment-to-invest point, and the variance was larger in P2 than in P1. The scores for estimating the overall out-turn cost (including design, works and supervision costs) were slightly lower in P2 than in P1 for three of the four submeasures, with an improvement shown in P2 where the actual out-turn cost was within $0 \cdot 16 \%$ of the estimated out-turn cost at agreement of the target price (awarded a KPI score of 10). However, cost predictability for both schemes was good, with all variances below 10\%. The HA's NEC option beta contract used for the CMF allows for a contractor's share, often referred to as the pain/gain mechanism. For CMF schemes, the maximum contractor's share percentage is awarded when the works cost is within 10\% of the agreed target price, and this is seen to be a driver for achieving better cost predictability in schemes.

Taking into consideration the client's opinion of the most important measures in delivering best value, P2 showed improvement compared to $\mathrm{P} 1$ in site safety with zero accidents reported during the second scheme. However, under-reporting of accidents has been highlighted as an inadequacy of using accident statistics as a performance measure. ${ }^{13}$ The CMF community makes efforts to overcome this by encouraging the reporting of accidents and near hits through inductions and workforce toolbox talks.

For the client's next two most important measures, namely customer satisfaction and defect-free work, there was also an improvement in the later scheme. This illustrates that clear improvements were shown in three of the client's four most relevant goals, with some improvement in cost predictability an indication that in areas seen to be significant to delivering best value by the client, improvements were visible when carrying out similar works using the same project team, 2 years later.

\section{TIME AND COST ACTUAL DATA}

While the KPIs measured predictability of time and cost, data from the two schemes can be compared to see if there were any actual savings made in these two areas. A comparison of the durations for the design, pricing and construction phases of the two projects is shown in Figure 4; a comparison of the costs is shown in Figure 5.

The comparison of durations (Figure 4) shows that the total duration of the second scheme was slightly shorter than the first; however, the design and construction phases actually took longer on P2. For the design, this may be a reflection of the measure, which took into account the start and end dates of the design and measured the time between the two dates. In reality, the duration of the design was less important than actually completing the design phase on time. The KPI measure for percentage variation of the duration of the design phase showed that a maximum score of 10 was achieved (see Figure 3); thus the design phase was completed within the duration predicted at the client's commitment-to-invest point, suggesting that the focus during this phase was maintained on the date that the design was required for the pricing phase.

The comparison of the two schemes shows an obvious improvement in the duration of the pricing phase in the second scheme compared to the first scheme. Pricing in P2 took just $41 \%$ of the time taken in P1 to complete this phase. This contributed significantly to the reduction in overall duration of

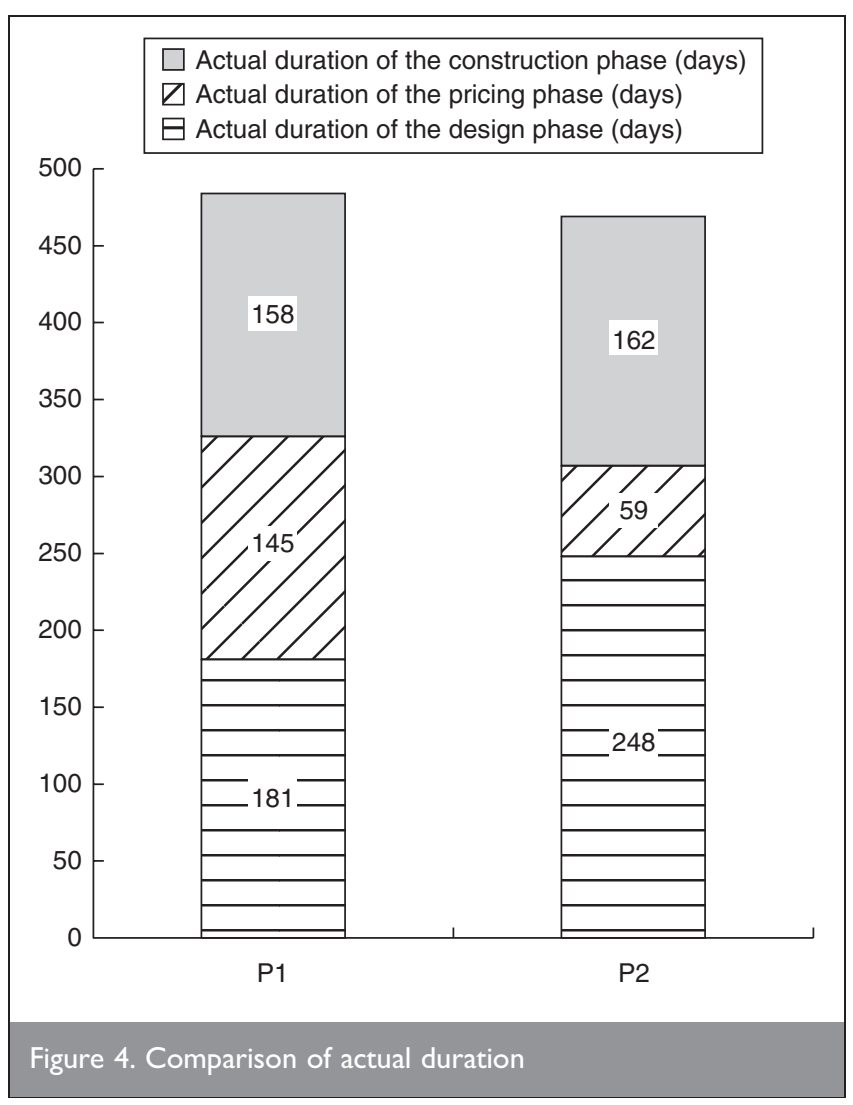




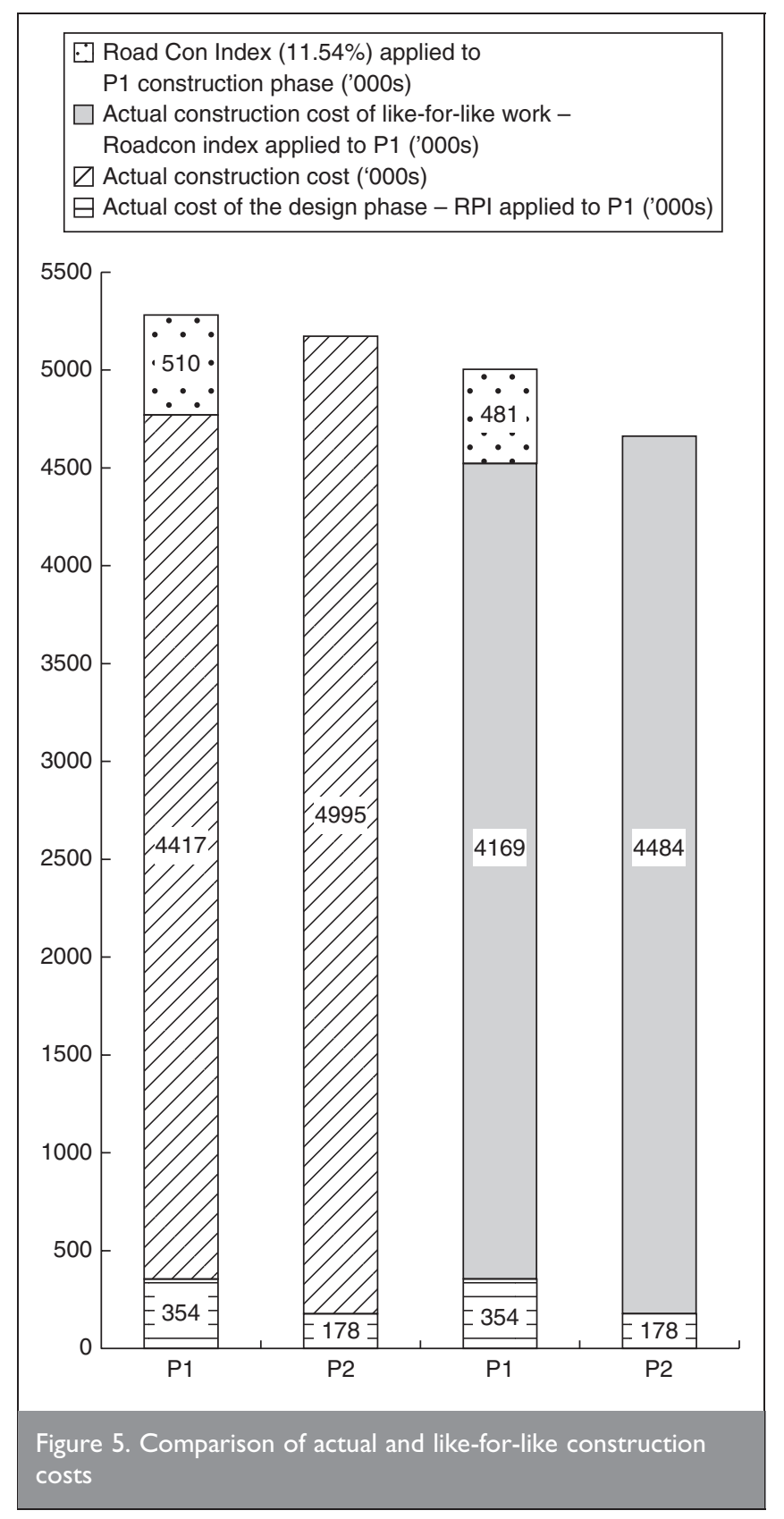

P2 compared to P1, compensating for the longer duration of the design phase in the second scheme.

Figure 5 shows a comparison of actual costs of the two projects. The retail price index (RPI) ${ }^{14}$ was applied to the P1 figure for the design phase to take into account inflation in employee rates, as the majority of the cost of design was man hours. Although some site investigation was allowed for, the two separate figures were not known, so the RPI was applied as a conservative figure. From the second quarter of 2004, to the second quarter of 2006, the RPI rose by 6\%. To compare the construction costs of the two schemes, the road con index ${ }^{15}$ was applied to the P1 figure to take into account labour and materials.

The results of the comparison of costs of the two schemes shows the cost of the design and construction of the P2 scheme was $2 \%$ lower than the cost of the P1 scheme. This was largely attributable to the lower cost of the design of P2, which was $50 \%$ of the design cost of P1.

\section{COMPARING LIKE-FOR-LIKE SCHEMES}

In comparing actual data of the construction phase of the two schemes, the results show that the duration of P2 increased by $2 \cdot 5 \%$ over P1, and the cost increased by $1 \cdot 4 \%$. However, in examining the breakdown of the construction costs, there were some differences between the two projects. The actual cost of the like-for-like construction, with costs deducted for works that were not duplicated on both schemes, is shown in Figure 5.

Works included in P1 that were not required for P2 were: construction of crossovers (since these same crossovers were used in P2 and therefore no further construction was required), and electrical works (including the removal of lights and light posts from the central reserve at the crossovers, and installation of lights in the verges of both carriageways). The cost of carrying out these works was deducted from the construction cost of P1.

Works included in P2 that were not required for P1 were: use of average speed cameras to record average speed of members of the public past the site works (to improve safety for road workers and maintain traffic throughput), installation of a gate in the crossover, and works as part of other schemes, including movement of steelwork to facilitate access under the viaduct, remedial works to plug joints and works to incorporate a future scheme for hard shoulder running through the site.

Some of the costs included in P2 were not directly related to the scheme; including these costs as a method of payment for these works was facilitated by the chosen procurement route. An advantage of working with the CMF identified by the client was the flexibility offered in taking on works outside the original scope. Adding extra work to a CMF contract using the traffic management and resources provided for in the original scheme reduced costs and afforded a speed of delivery not otherwise possible.

Deducting the costs for the work not duplicated in both schemes allows a comparison of like-for-like schemes to be made. On this basis, it can be identified that a saving of $6 \cdot 8 \%$ for design and construction costs is visible on P2 when compared with P1. If the exercise of comparing the durations for carrying out likefor-like work is done, the programmes of the two schemes in terms of the time from opening to closing of the crossovers show a 13\% saving in time was achieved in P2.

In summary, this scheme demonstrates savings of $6 \cdot 8 \%$ in design and construction costs and 13\% in time of like-for-like construction, that has been achieved using the same team of designers, specialist framework contractors and construction manager who have built up a working relationship over 2 years within the organisation of the CMF community.

\section{CHANGES IN WORKS INFORMATION}

All communications on the CMF sites were undertaken using a site record system. Every site record was entered onto a register which identified if the communication was an early warning. In line with the NEC early warning procedure, it was noted whether the early warning formed a compensation event, in which case an instruction to submit quotations was formalised. Quotes were then received from the specialist framework contractor and the cost was added to the agreed target price (or 
deducted from the target in the case of a negative compensation event).

Under NEC contracts, compensation events apply to changes made by the employer and to claim type issues. ${ }^{10}$ The NEC contracts used in the CMF are cost reimbursable against an agreed target price, which means compensation events acknowledge changes to time and cost, and allow the target price to move in line with those changes. This reduces the attraction for contractors to submit dubious claims and encourages prompt attention to issues and settlement of accounts.

In P1, there were 193 compensation events; in P2, there were 65 compensation events, 34\% of the number of compensation events raised in P1. This could indicate: far fewer changes to the works were instructed in $\mathrm{P} 2$ than in P1, possibly due to the greater certainty achieved in $\mathrm{P} 2$ having already completed $\mathrm{P} 1$; a shift in mentality and culture from a conventional contracting environment where claims were submitted in an attempt to increase profits to a more cooperative relationship in solving problems and agreeing a way forward.

In addition, the ECI process established in the first CM pilot was well-established by the CM community when P2 was developed. The ECI process allows specialist framework contractors to give input to the scheme design to develop the optimum solution with the designers. Establishing the ECI process for P2 meant that specialist framework contractors, the designers and the construction manager, having already established a working relationship on $\mathrm{P} 1$, were able to share knowledge and experience to contribute to the best solution for P2, including the lessons learned from the first scheme. This meant the design was well developed for the construction phase, thus reducing the need for changing the works information on site.

\section{INNOVATIONS AND LESSONS LEARNED}

Providing innovations was promoted by the CMF as a way to create client value. ${ }^{6}$ An innovation register was established on every CMF scheme at design stage and continued through the construction phase. The register detailed the innovation, or good idea, including the benefits it provided and the value of the innovation, which should have included a cost saving if relevant. Innovations were encouraged from the workforce with posters on site and prizes determined by individual sites. At design stage, innovations registers from previous schemes were reviewed so that any suggestions that were applicable could be considered for implementation.

Figure 6 illustrates the number of innovations proposed and implemented on P2. There were 13 innovations proposed during $\mathrm{P} 2$, of which eight were implemented; one of these was proposed during the design stage, with the remaining number in the construction phase. In addition, eight innovations that had been implemented in P1 were employed in P2 and a further five innovations from other CMF schemes, which were identified as being good practice, were used on $\mathrm{P} 2$.

In P1, there were 14 innovations proposed, of which 13 were implemented. As P1 was undertaken early in the life of the $\mathrm{CMF}$, no other innovations were shared from the CMF or

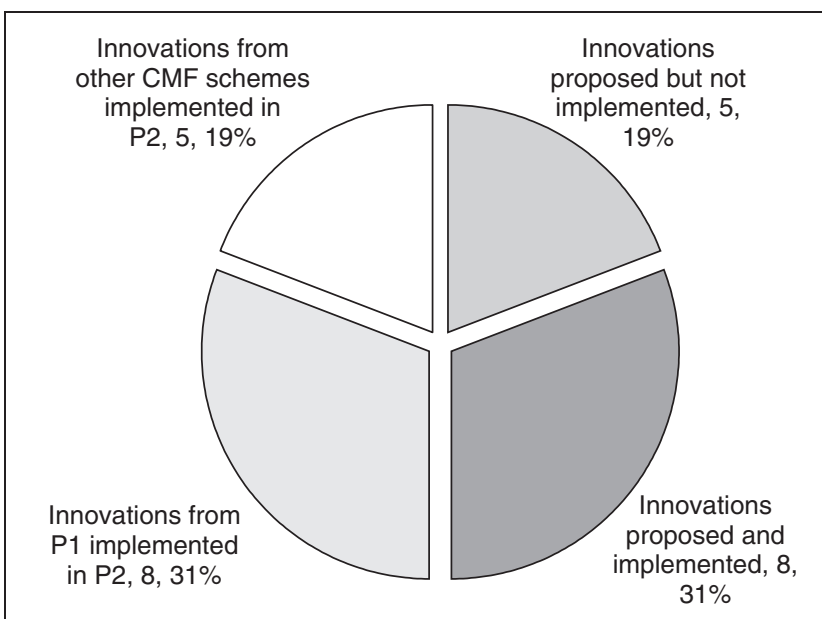

Figure 6. P2 innovations

previous schemes. However, the implementation of 21 innovations in P2 indicates the opportunity for pooling innovations from previous schemes, both similar and diverse across the CMF, and assessing their suitability to future schemes for implementation of those that will provide value. Savings from the innovations implemented in P2 were valued at around $£ 250000$ : 5\% of the construction cost of the project.

A significant innovation implemented in P2 was the use of average speed cameras, which measured the average speed of drivers between two points, with the intention that a consistent safe speed was maintained. While there was a large expense attached to implementing the cameras, the need to slow traffic past the worksite as a safety issue was identified in P1, and the flow of traffic was improved. Road traffic accidents recorded within the site numbered 12 during P1; this fell to seven in P2. This may be some indication of the effectiveness of the average speed cameras in reducing traffic accidents by providing a steadier traffic flow.

On completion of P1, 36 key lessons learned were identified. These were categorised as: health and safety, planning/design stage, construction, planning during construction and working as a team. Eighteen of the lessons learned were areas that could have been improved, while the other 18 were practices on site that had a positive effect, and provided guidance for other sites. The lessons learned that highlighted areas that could have been improved included: storage of materials on site should be better planned to make best use of the available space; permits to work should be discussed at the beginning of a scheme so that systems are in place from start; the scope of emergency works (responsibility for carrying out emergency works, e.g. patching of potholes, and limits of areas of responsibility) should be discussed in detail prior to scheme start; protection to areas affected by the works (but not included in the works) should be determined at the ECI stage; and lessons learned should be discussed on a weekly basis as a team, rather than at the end of the scheme.

There were nine key lessons learned that were identified on completion of $\mathrm{P} 2$, with the majority of these being actions that 
had been undertaken during the scheme which showed a benefit. Only one lesson was the result of an area identified for improvement on site. Many of the lessons learned from P1 were addressed in P2, including those described above. In addition, the lesson learned from P1 were communicated to the CMF community as good practice and adopted on other schemes.

In reviewing and implementing practices to address lessons learned from P1, an improvement was demonstrated in the second scheme, with the recording of one lesson learned resulting from an area that showed some failing - a significant improvement on the 18 lessons learned identified in the first scheme. This improvement was a particular indication that use of the same team of designers, construction manager and specialist framework contractors helped to avoid problems encountered on the earlier scheme.

\section{RESPECT FOR PEOPLE}

A respect for people survey was carried out as one of the processes conducted as part of CMF projects, approximately 1 month into the construction phase of each project. The survey consisted of 34 questions, separated into three categories:

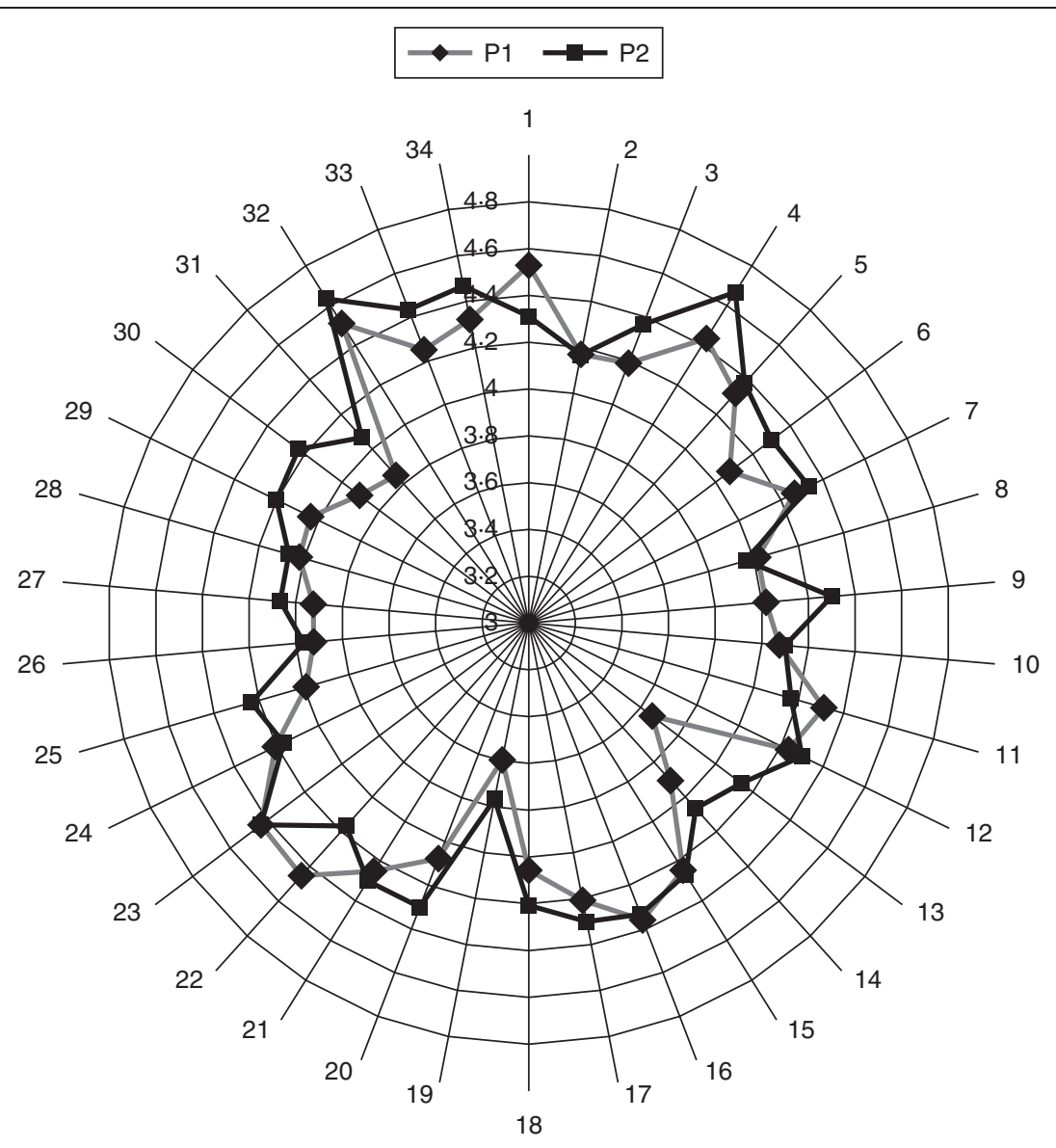

Respect

1. I am satisfied with the respect I get from my supervisor/manager on this site

2. On this site, people listen and respond when I make suggestions

3. On this site, people listen and respond when I have a problem

4. I am treated fairly on this site

5. In general, the relations between managers and operatives here are good

6. On this site, my work seems to be valued

7. On this site I have the resources I need to do my work right

8. When I need information on this site, people respond quickly

9. I feel that my views are listened to on this site

10. I never feel that my time is wasted on this site

11. On this site the right people attend meetings consistently

12. On this site, managers acknowledge me

13. I think the welfare facilities on this site are good

14. In CMF people work together and cooperate with each other

15. I am proud to tell people I work in CMF

\section{Integrity}

16. On this site, I get help when I need it

17. On this site, I am usually provided with clear and adequate information

18. On this site, communication is open at all levels

19. On this site, people acknowledge their weaknesses

20. In general, people are positive about working in CMF

21. I get a good sense of achievement from my work on this site

22. On this site, my co-workers are committed to doing quality work

\section{Reliability}

23. I am satisfied with the hours I work on this site

24. Managers here keep everyone up to date with changes

25. On this site the managers give praise for good work

26. On this site my supervisor/manager and I often discuss how I am getting on with my job

27. On this site, I am satisfied with the amount of influence I have over my job

28. On this site, I am offered the training I need to do my job

29. I feel I get support in this team

30. On this site, I get an opportunity to express my views

31. On this site, everyone is given the chance to comment on proposed changes

32. I understand my role on this site

33. In general, relationships between specialists on this site are good

34. I feel part of this site team 
respect, integrity and reliability. Each question was given a score from 0 to 5 by the respondents, with 0 marked for strongly disagree, and 5 for strongly agree. Surveys were issued to all on site, including operatives, supervisors and managers, and it was intended that the survey would reflect the standard of the site in terms of the way people felt they were being treated. When areas for improvement were highlighted, it was expected that management on the site would formulate an action plan for improvement, and, if appropriate, another survey might be carried out, particularly on projects of longer duration (6 months or more).

The results of the respect for people surveys carried out on both scheme is shown in Figure 7. The results mainly demonstrate an improvement from P1 to P2, with higher scores achieved in P2 for 85\% of the questions. For the three sections of respect, integrity and reliability, the average scores were: $4 \cdot 16,4 \cdot 09$ and $4 \cdot 14$, respectively, for P1, and $4 \cdot 26,4 \cdot 20$ and 4.24 for P2, thus showing an improvement in each section from $\mathrm{P} 1$ to $\mathrm{P} 2$.

The results of the respect for people survey demonstrate that the workforce on the whole are more satisfied with the environment, conditions and treatment that they received on the second scheme when compared with the similar type of work scheme carried out 2 years earlier. This would suggest improvements have been made in terms of respect for the workforce as time has progressed.

\section{FINDINGS}

In examining two schemes with similar work packages, carried out 2 years apart, using the same project team under a framework arrangement with its own processes and procedures in place, improvements have been demonstrated. These are shown by the following actions.

(a) Better results of performance measures, particularly with respect to time predictability, site safety, customer satisfaction and defect-free work, these measures being perceived by the client to be important to achieving best value.

(b) Shorter duration and lower costs when comparing like-forlike work.

(c) A smaller number of compensation events, indicating fewer changes to works information, partly made possible through the ECI process.

(d) The use of innovations to contribute to savings in the region of 5\% of construction costs.

(e) Recording of lessons learned from 18 in P1 resulting from areas for improvement, to just one in $\mathrm{P} 2$.

(f) Improvements in respect for people surveys in $85 \%$ of the survey questions.

The comparison of the two schemes has shown that improvements have been made in the three cornerstones to the CMF community: measurement, process and culture. For measurement, the KPI results show an overall improvement over the 2 years from P1 to P2 with positive actual data comparisons. For processes, the advantages of implementing innovations and lessons learned within a framework setting have been shown, while the success of implementing the culture of the CMF is evident through the improved respect for people results.
This particular case study has shown the benefits in the context of the CMF, where the same project team of client, construction manager and specialist framework contractors has worked within its contractual obligations of the NEC contract, which encourages partnering with a spirit of mutual trust and cooperation. There was also the added incentive of the HA's Option Beta contract, based on a target cost with the contractor's share to encourage savings, with a special condition for specialist framework contractors to contribute to continuous improvement and innovation. This is further facilitated using construction management as the procurement arrangement, where specialist framework contractors who may be more traditionally part of a supply chain have a direct contractual relationship with the client. The CMF community has been established to develop the processes to operate the framework contract, and to provide a forum for learning and sharing best practice. Thus the basis of the framework, the contractual arrangement under which each party operates, is directed towards achieving continuous improvement, and this is facilitated by the community, which provides the forum for knowledge sharing. Finally, the relationship of the parties involved, which was established in the first scheme and developed through working on subsequent projects, has contributed to tangible improvements and savings demonstrated in this case study.

\section{REFERENCES}

1. Haynes L. and Roden N. Commercialising the management and maintenance of trunk roads in the United Kingdom.

Transportation, 1999, 26, No. 1, 31-54.

2. See http://www.highways.gov.uk/roads/14498.aspx. Accessed 06/04/2009.

3. Construction Management Community. Community Manual. Construction Management Community, Newcastle-underLyme, 2004.

4. Highways Agency. Delivering Best Value Solutions and Services: HA Procurement Strategy. Highways Agency, London, 2001.

5. LAtham M. Constructing the Team: Joint Review of Procurement and Contractual Arrangements in the United Kingdom Construction Industry: Final Report. HMSO, London, 1994.

6. National Audit Office. Modernising Construction. The Stationery Office, London, 2001.

7. Egan J. L. Rethinking Construction: the Report of the Construction Task Force to the Deputy Prime Minister, John Prescott, on the Scope for Improving the Quality and Efficiency of UK Construction. Department of the Environment, Transport and the Regions, London, 1998.

8. Construction Management Community. 2004 Annual Report. Construction Management Community, Newcastle-underLyme, 2004.

9. BRYDE D. J. and BRown D. The influence of a project performance measurement system on the success of a contract for maintaining motorways and trunk roads. Project Management Journal, 2004, 35, No. 4, 57-65.

10. LeWEndon R. NEC: Engineering and Construction Contract. Module 1 - An Introduction. Roger Lewendon Associates, London, 2004.

11. Halcrow Group Limited. Construction Management Framework Value for Money Study. Halcrow Group Limited, York, 2006. 
12. Ansell M. Best Value in Highways Maintenance. MSc dissertation, Loughborough University, 2006.

13. COOPER M. Current issues in health and safety training in the UK. Journal of European Industrial Training, 1998, 22, No. 9, 354-361.
14. See http://www.statistics.gov.uk/statbase. Accessed 06/04/ 2009.

15. Patel S. Value for Money Report. AmeyMouchel, Telford, 2006, Internal Report.

\section{What do you think?}

To comment on this paper, please email up to 500 words to the editor at journals@ice.org.uk

Proceedings journals rely entirely on contributions sent in by civil engineers and related professionals, academics and students. Papers should be $2000-5000$ words long, with adequate illustrations and references. Please visit www.thomastelford.com/journals for author guidelines and further details. 